\title{
Conversion of a Conventional Bench Lathe to CNC Machine
}

\author{
Perry S. Koradiya, Aman H. Kania, Hemanshu S. Vankhede, Parth A. Patel, Chinmay K. Desai
}

\begin{abstract}
In this paper we report about our experience related to the development of low cost machine tools retrofit based principally on the implementation of universal Mach3 software, that it allows a quick and easy adaption of new components to integrate the machine tool. It aims to provide a low cost alternative to solve this problems, and in this way to generate greater competencies in industrial and manufacturing system. This technique is aimed at strengthening modernization and helps to grow the metal working industry in MSMEs and SMEs, as well as support to the education sector in developing countries.

Nowadays, products are manufactured using modern technology which employs a communion of computer software, hardware and firmware and lathe machines play a vital role in manufacturing sector. While the manual lathe machines are more economical, they require to be operated by highly skilled workers otherwise their accuracy and efficiency is not up to the mark on the other hand, CNC machine provide the desired accuracy and efficiency of output, but require a huge capital. This can be done using an ARM processor to control the functioning of the lathe machine.
\end{abstract}

Index Terms - Automation, CNC Turning center, Low Cost, Machine Tools, Universal Numerical Control, Reconfigurable.

\section{INTRODUCTION}

Retrofitting refers to the addition of new technology or features to older systems this definition gives an almost all information about the word retrofitting. When we say that retrofitting related to some component that mean we try to upgrade that component and improve their efficiency through a present technology.

Here we are concerned with retrofitting in a Bench lathe machine. At times, Retrofitting is the process of replacing the $\mathrm{CNC}$, servo and spindle systems on an otherwise mechanically sound machine tool to extend its useful life. Rebuilding and remanufacturing typically include a CNC retrofit. The anticipated benefits include a lower cost investment than purchasing a new machine and an improvement in uptime and availability. But there are often other unanticipated benefits to retrofitting including lower energy costs, higher performance and a new level of manufacturing data accessibility.

Assuming the machine tool is generally in good shape mechanically, $\mathrm{CNC}$ retrofitting is typically the lowest cost

Perry S. Koradiya, UG Student, B.Tech Mechanical Engineering, C.G.P.I.T. UKA Tarsadia University

Aman H. Kania, UG Student, B.Tech Mechanical Engineering, C.G.P.I.T. UKA Tarsadia University

Hemanshu S. Vankhede, UG Student, B.Tech Mechanical Engineering, C.G.P.I.T. UKA Tarsadia University

Parth A. Patel, UG Student, B.Tech Mechanical Engineering, C.G.P.I.T. UKA Tarsadia University

Chinmay K. Desai, H.O.D. Mechanical Department, B.Tech Mechanical Engineering, C.G.P.I.T. UKA Tarsadia University solution to improve the overall performance of an older machine tool.

Though some electrical subassembly is often performed at the retrofitter's business location, most of the work can be completed at the machine site, avoiding costly machine rigging and transportation costs, and minimizing the time that the machine is out of commission.

Rebuilding typically includes the repair or replacement of some worn mechanical components such as ball screws, lubrication pumps, safety interlocks, guards, hoses, belts and electrical wiring. The rebuild is typically performed at the rebuilder's facility, so there may be additional transportation and rigging costs. [1]

Remanufacturing goes a step further to repair or replace mechanical components to the original, as new, factory specification. It is likely that the machine will be completely disassembled, cleaned, inspected, repaired and painted. All pneumatic, hydraulic and electrical systems will be updated. The machine may also be modified or have mechanical accessories added to re-purpose it for a new application. Practically without exception, remanufacturing will take place at the remanufacturer's site.

The main objective of the retrofitting in a Bench lathe machine is to improve the existing conventional Bench lathe machine to provide it features of CNC machine with very lower cost than the new $\mathrm{CNC}$ machine.

Rather than above main objective there also several objectives of the retrofitting which is given below

$\checkmark$ To Increased productivity and improved control of machine.

$\checkmark$ Far superior repeatability.

$\checkmark$ To reduced machine downtime.

$\checkmark$ Fast machining cycles.

$\checkmark$ High accuracy, high feed-rate.

$\checkmark$ To increased accuracy and part finished due to controller.

$\checkmark$ User friendly programming and simulation software enables 3D graphic representation of job with automatic generation of G-Code.

$\checkmark$ Eliminate additional tooling cost.

$\checkmark$ The Up-gradation Package is less expensive and more readily justifiable.

$\checkmark$

\section{LITERATURE REVIEW}

In 1984, Department of Mechanical Engineering, IIT, New Delhi [1], has taken a research topic named as "Machine tool failure data analysis for condition monitoring application". With the development of modern manufacturing technology, Flexible Manufacturing Systems have become key equipment 
in factory automation. Machine tool is heart of the Flexible Manufacturing Systems. Ex example Lathe machine is the general type of machine tool used by almost all the FMSs. During the operation of this machine tool, different kinds of failures are faced by the industry. A systematic study of such failures can help in identifying the critical sub-system of these machine tools. This will be useful for identifying the condition monitoring needs of the machine tools. This deals with the identification of critical sub-system based on the failure data analysis for different type of machine tools.

Initially lathe has been classified into various sub-systems as shown in Figure. In the frequency of failures for each subsystem and failure modes have been considered for finding out the weakest sub-system. In analysis, failure frequency and downtime have been taken into consideration for deciding critical sub-systems of machine tools. It can be observed that the maximum failures took place in headstock and carriage sub-systems. These sub-systems face failures in components like gear, gearbox bearing, spindle bearing, clutch and cross slide jib. Here it could be observed that the bearing failures cause longer downtime.

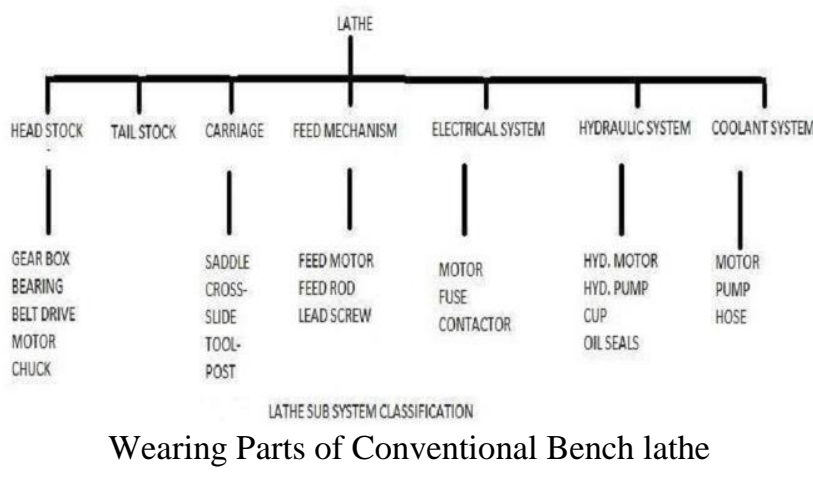

On histogram different failure modes and their relative failure frequencies have been grouped into four-failure modes, component damage, fuse burnt, circuit fault and looseness. It can be observed that the dominant failure mode is because of component damage. The components are electrical, electronics and of mechanical categories.

In 2013, V. Roy \& S. Kumar [2] from J institute Engineering, India published development of Lathe machine attachment for CNC machine.

He has developed attachment for an existing CNC machine. The CNC machine operates on mechatronic controls and a computer interface called CAMSOFT, and is used as a CNC Lathe after installing the respective attachment to it. He has design the attachment using CAD software \& fabricated different model. He has successfully design \& fabricated the model. The working of the CNC Lathe attachment is tested \& checked by making proper machining operation like turning and thread cutting. The machining operations are successfully done. The CNC machine becomes multifunctional with the presently developed lathe attachment and can be used accordingly by installing the respective attachment to it. The CNC machine is useful for research work in both the fields, when installed with the proper attachment. The figure of developed attachment is shown below,

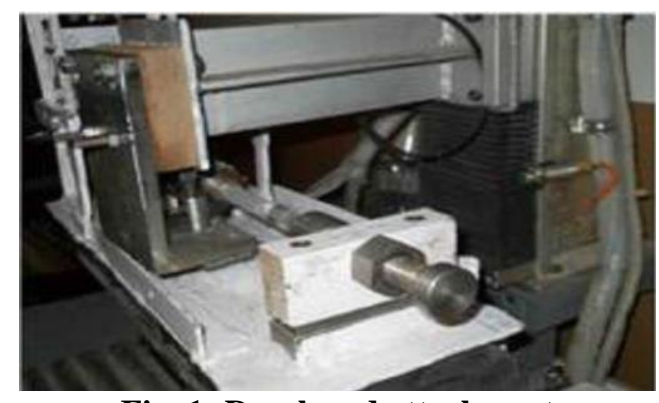

Fig. 1: Developed attachment

Developed design is successfully implemented in the proposed work for the development of the lathe attachment including headstock, tailstock and tool post. The work shows the process of the conceptual design and use of proper process planning for the development of the different components of the lathe attachment. The previously attachment and developed lathe attachment make the CNC machine multifunctional. Thus further research can be carried out in both the fields respectively. The CNC machine is based on the mechatronic controls and the computer interface CAMSOFT. Various lathe operations like plain turning, step turning, taper turning, arc turning, threading operations and manufacturing of a bolt are successfully performed on the CNC machine, when installed with lathe attachment. The successful development of the lathe attachment for the CNC machine is done.

In 2013, Karl-Heinz Schumacher [3] is invented about Multi Spindle Lathe.

Multi spindle lathe comprising a machine frame as spindle drum which is arranged in the machine frame is rotatable about a spindle drum axis and is made up at least partially of segments which are cut out from flat material in a stacking direction parallel to the spindle drum axis and extend in stacking planes transverse to the stacking direction these segments having receiving cutouts and cooling channel cutouts which overlap with one another such that the spindle drum has spindle motor receptacles for spindle motors and a cooling channel system separated there from by wall webs characterized in that the cooling channel system has several channel subsystems for a liquid cooling medium Which are fed in parallel.

In 2013, M. Moses \& Dr. Denis Ashok [4] M. Tech, Mechatronic from School of Mechanical and Building Science, VIT University, Vellore, India published titled as Development of a new machining setup for energy efficient turning process. In the production unit, lathe is one of the important protection machines. This paper focuses on producing a quality product in lathe machine with less power consumption. In order to achieve that, a special setup is developed in the lathe machine for turning and finishing of the components, to achieve quality product and also to improve the productivity. As a result of this new approach, profuse amount of energy can be saved, quality product can be obtained and tool life can be increased. The study aimed at evaluating the best process environment which could simultaneously satisfy requirements of both quality and as well as productivity. By conducting many experiments it was found that this special setup process improves the quality and also reduces the power consumption as compared with the existing process. 
International Journal of Engineering and Technical Research (IJETR)

ISSN: 2321-0869 (O) 2454-4698 (P) Volume-8, Issue-12, December 2018

Figure of developed attachment as shown below,

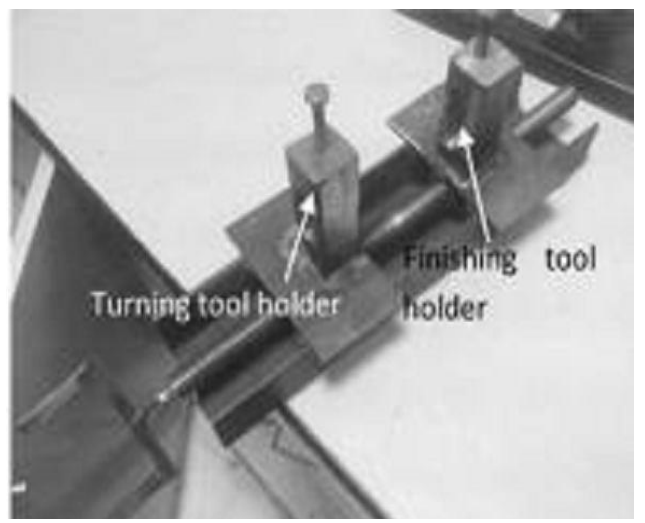

Fig. 2: Machine set up

He has concluded that the addition of surface finish tool in turning process helps to improve the surface finish and this setup increases the tool life of the turning tool. From the experimental results, it is confirmed that there is no change of power consumption even after the additional usage of surface finish tool. Hence, the set up will be helpful in improving the quality product, with lesser load and power consumption.

III. SYSTEM OVERVIEW \& SCHEMATIC WORK

Retrofitting refers to the addition of new technology or features to older systems this definition gives an almost all information about the word retrofitting. When we say that retrofitting related to some component that mean we try to upgrade that component and improve their efficiency through a present technology. Here we are concerned with retrofitting in a Bench lathe machine. At times, Retrofitting is the process of replacing the $\mathrm{CNC}$, servo and spindle systems on an otherwise mechanically sound machine tool to extend its useful life. Rebuilding and remanufacturing typically include a CNC retrofit. The anticipated benefits include a lower cost investment than purchasing a new machine and an improvement in uptime and availability. But there are often other unanticipated benefits to retrofitting including lower energy costs, higher performance and a new level of manufacturing data accessibility. Assuming the machine tool is generally in good shape mechanically, $\mathrm{CNC}$ retrofitting is typically the lowest cost solution to improve the overall performance of an older machine tool.

\subsection{Problem Overview}

Cutting depth irregularities

$>$ Wastage of time

$>$ Low accuracy due to double loss

$>$ Spacing issues

$>$ Problem with coolant

Motor position for cutter

$>$ High production cost

\section{CONVERSION PROCEDURE}

Here I have divide the complete construction procedure into five steps. In which I have developed the complete Converted lathe machine from conventional lathe machine.

These all steps are listed below,
Step 1:- Purchasing of electronic parts

I have purchased electronic parts like stepper motor, stepper drive, spindle drive, Limit switches, Emergency Stop Button.

Step 2:- Disassemble some parts from conventional Bench lathe machine.

As per definition of retrofitting process, I have to remove non-used parts from conventional lathe machine. So I have removed Head stock gearing mechanism, Apron, Lead screw, Lead screw mounting bracket, Hand wheel, etc.

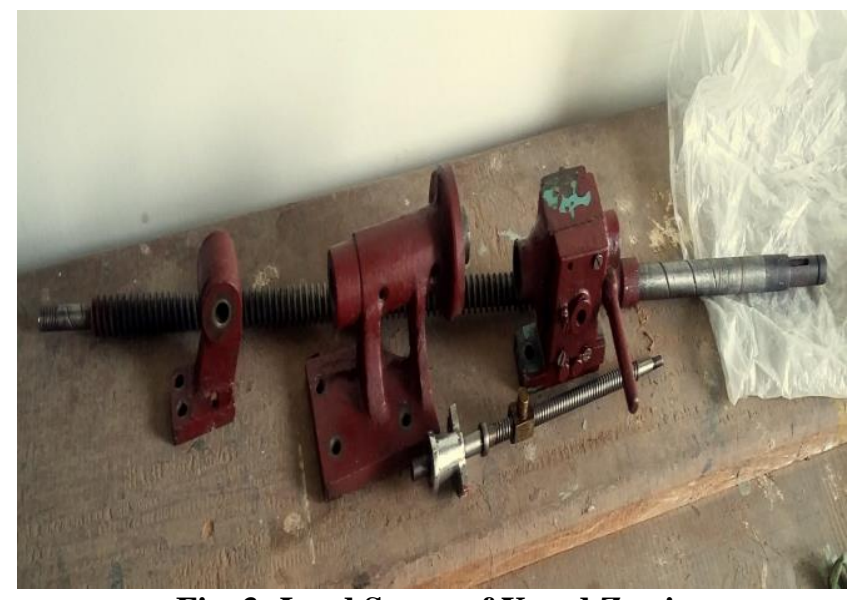

Fig. 3: Lead Screw of $\mathrm{X}$ and $\mathrm{Z}$ axis
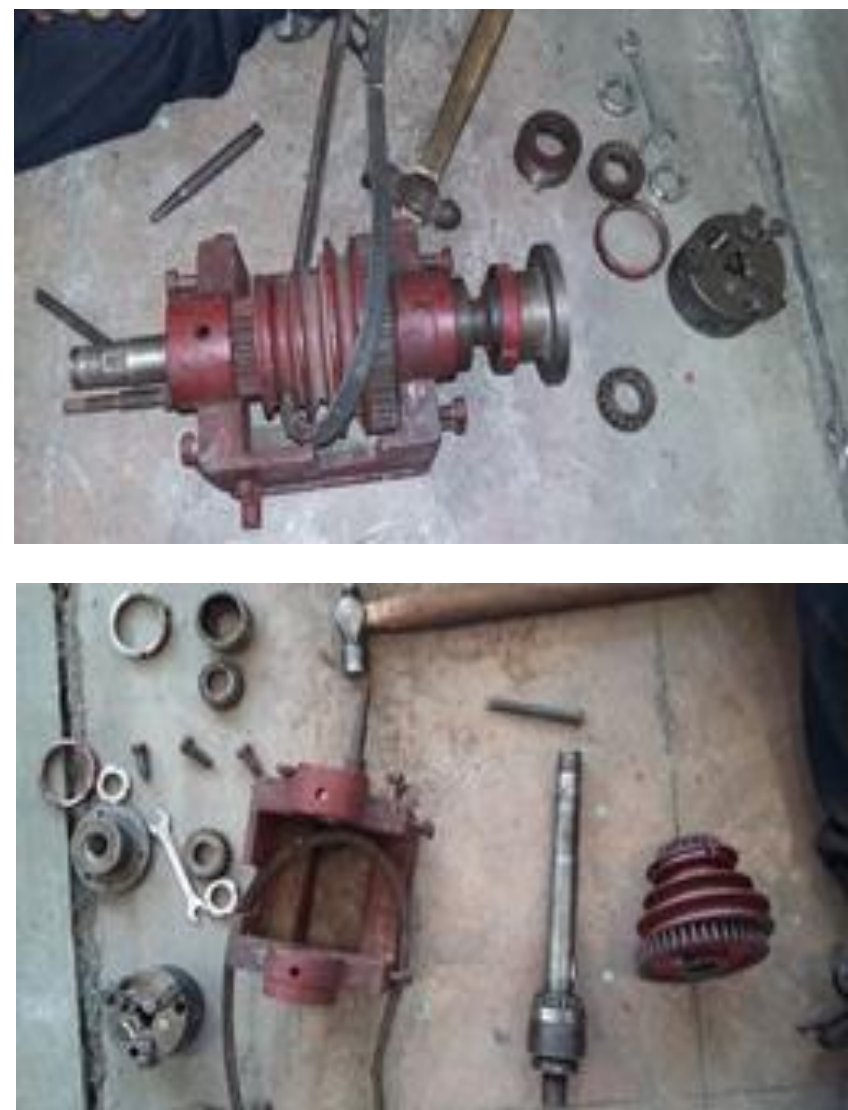

Fig. 4: Removal of Head Stock Gearing Mechanism

Step 3:- Dimensionally Design and fabrication of required mechanical parts.

I have dimensionally design some parts which are required for retrofitting \& fabricated and/or manufactured. Some of parts design are shown below. 

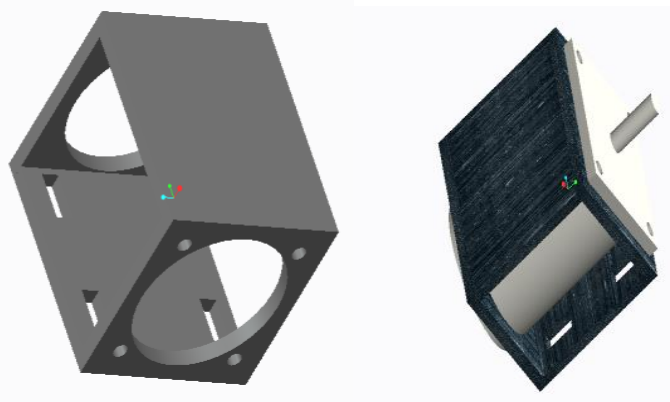

Fig. 5: Z-axis Motor Bracket

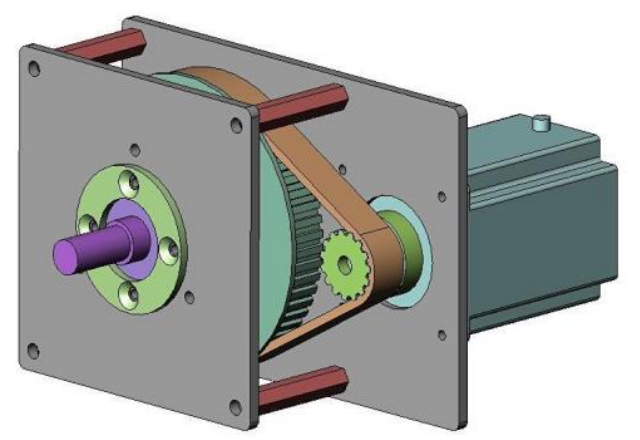

Fig. 6: Assembly of Stepper Motor into Mounting Bracket

Step 4:- Assemble all manufactured parts \& electronics parts at desired place.

After manufacturing and/or fabricating all required parts, assembly procedure carried out. All the mechanical \& electronics parts are attached to their desired place. Some of parts are shown below
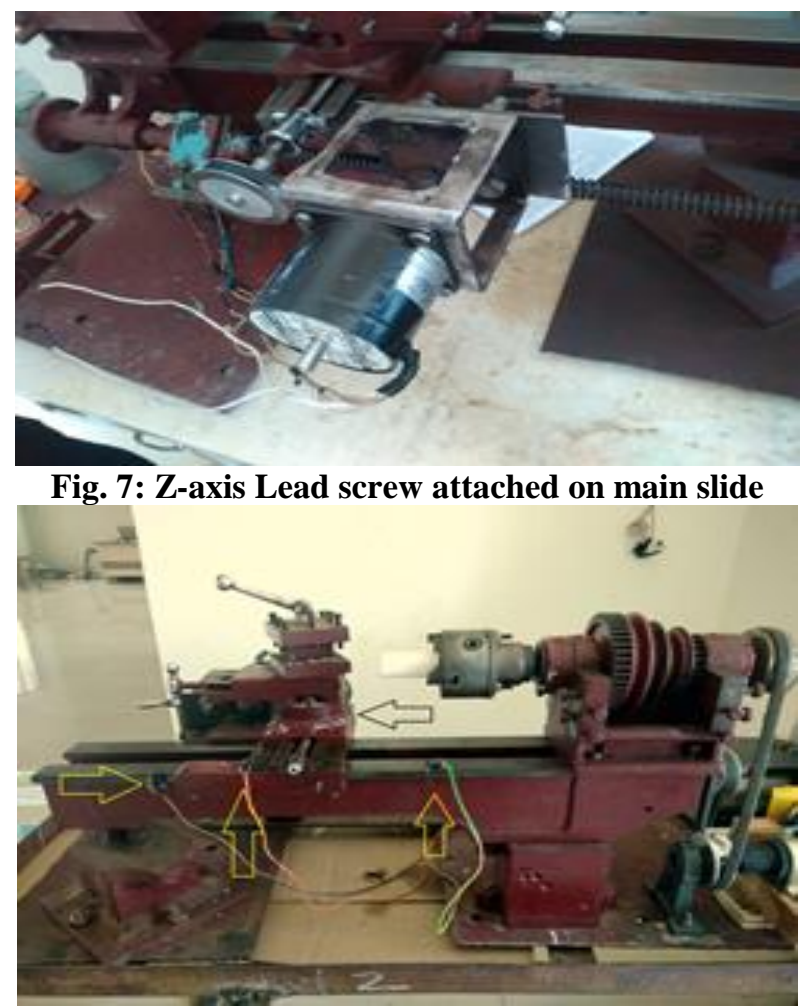

Fig. 8: Limit switches

I have attached Limit Switches at the end of the $\mathrm{X} \& \mathrm{Z}$ axis of the ball screw as a safety device.
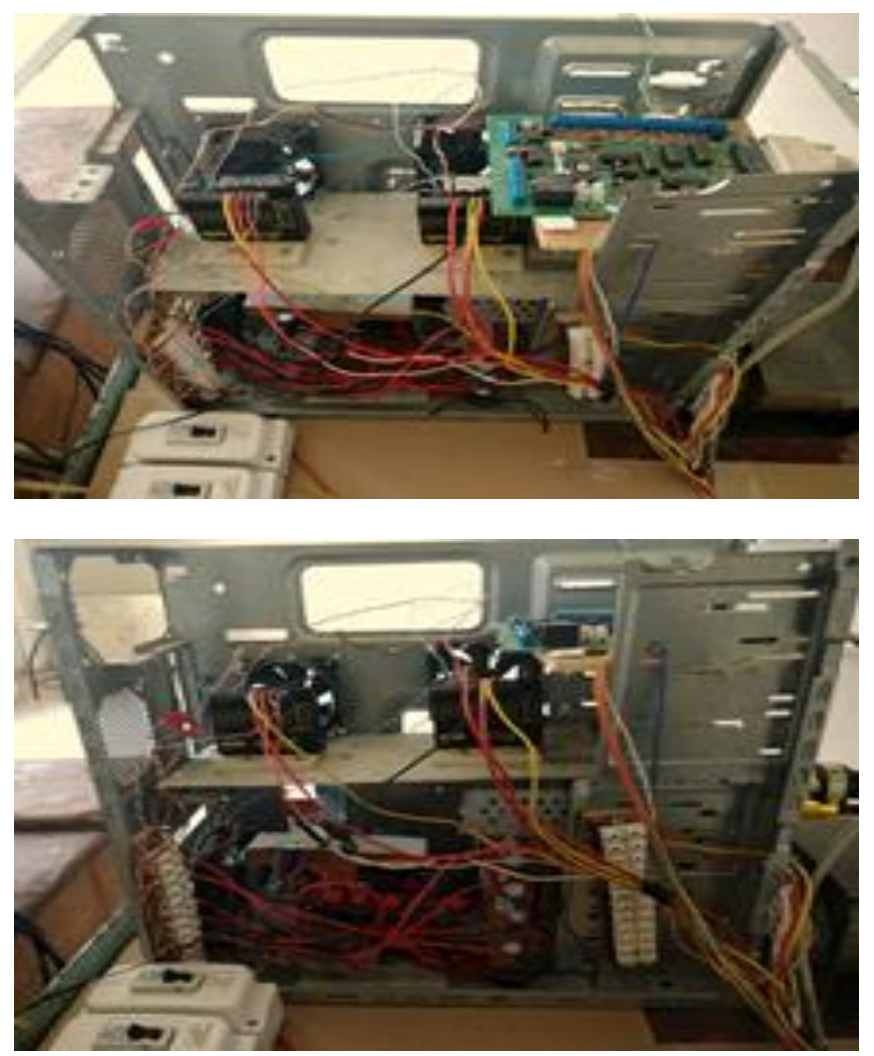

Fig. 9: Control panel

Control Box is shown in figure here $\mathrm{C} 11 \mathrm{G}$ Multi-Functional CNC Board is used for the controlling of two stepper motors on programming based Mach-3 software.

Step 5:- Inspection \& testing of new developed Retrofitted Bench Lathe Machine.

In this step I have checked all components are properly fitted with machine body and alignment of both Lead screws. Also checked both slide working properly by stepper Motor.

Then I have manufactured job on developed Converted lathe machine by using turning operation program which is from manual part program method and checked surface finishing of the job.

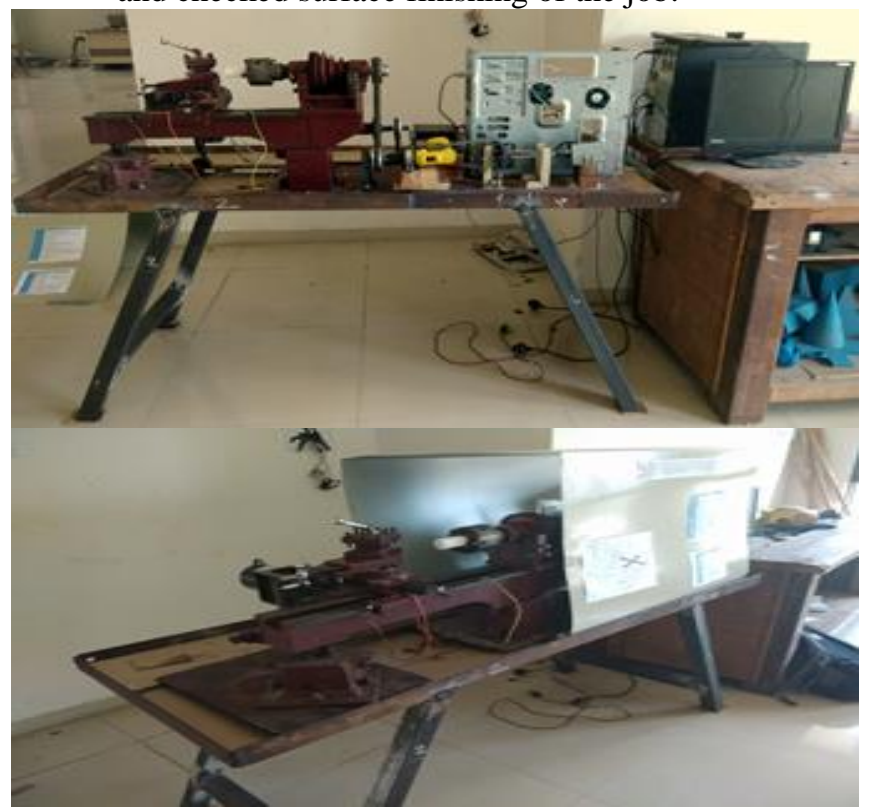

Fig. 10: Developed converted lathe machine 


\section{COMPARISON}

For comparison I have compare job manufactured on conventional Bench lathe machine \& job manufactured on developed Converted Bench lathe machine.

And I have concluded that surface roughness, production rate, dimension stability, one time set up cost is high in Converted lathe machine while machining time, machine slide wear is too much low.

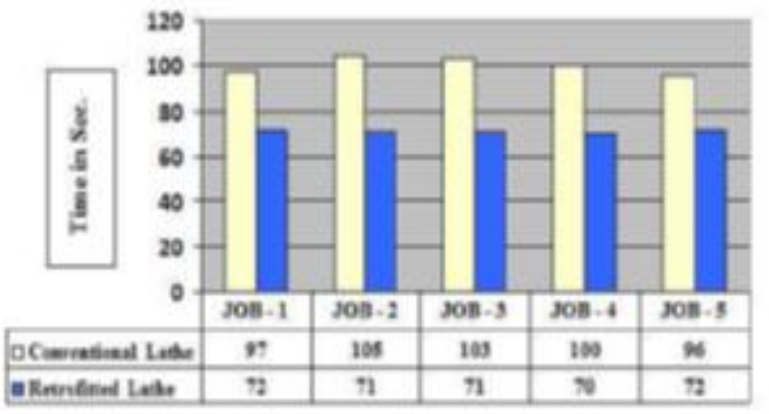

Fig.11: Comparison of machining time between job manufactured on proposed \& existing lathe.

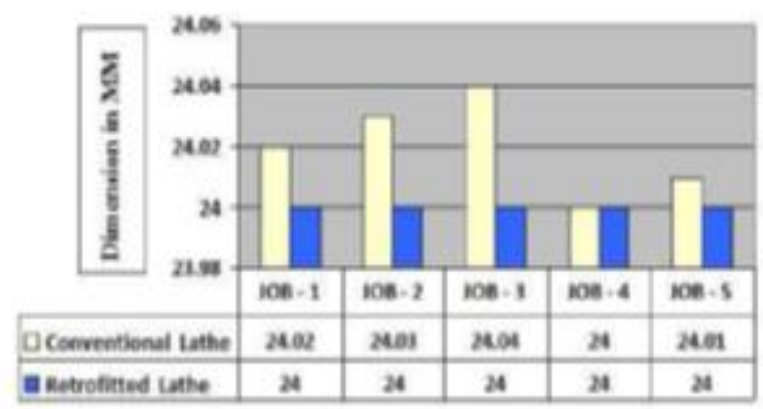

Fig.12: Comparison of job dimension between proposed \& existing lathe machine.

The job manufactured on both the machine are shown below,
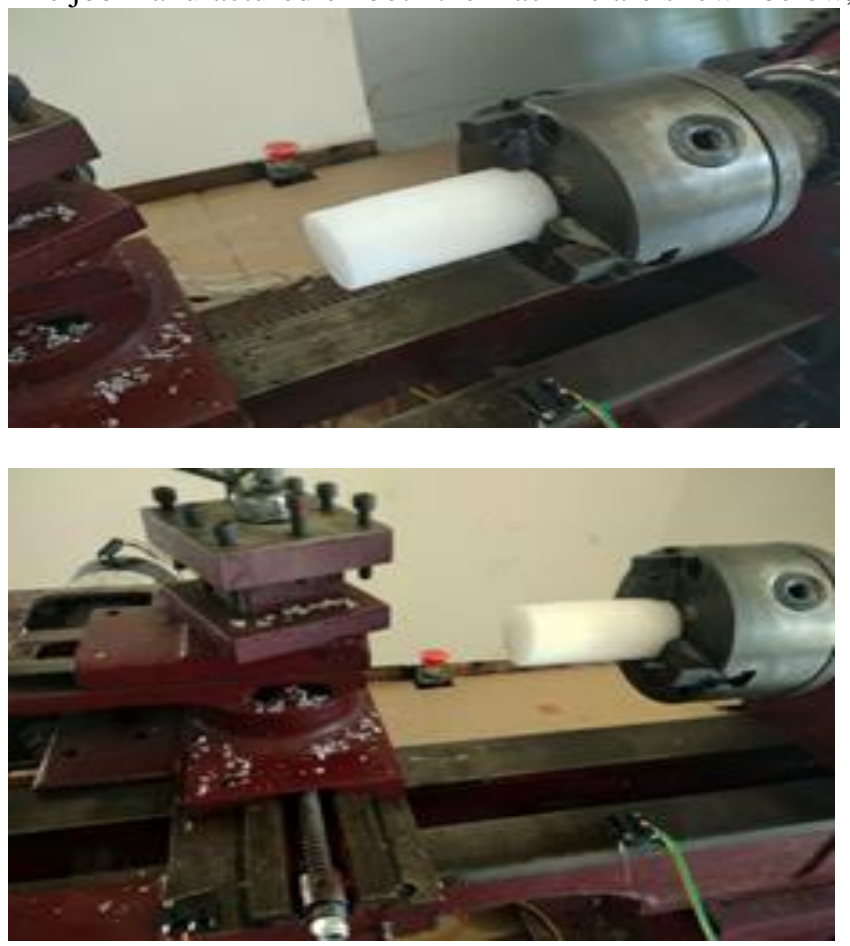

Fig. 13: Job Sample

\section{CONCLUSION}

By developing automation in conventional lathe machine by retrofitting stepper based method, the machine works as CNC trainer for teaching, learning of the student subject. Also Cost of machine is minimizes approximate 4 times below the original CNC trainer.

As automation new developed Converted Bench lathe is done by replacing or removing the components from conventional lathe machine, therefore setup cost is high as compare with standard lathe machine but production rate is too much high. So it is very useful for mass production. The accuracy of the job manufactured in Converted lathe machine is also high so repeatability and dimensional stability of manufactured part is achieved. At last some complex job which is not manufactured in conventional lathe machine can be manufactured in new developed retrofitted lathe machine.

\section{REFERENCES}

[1]Machine Tool Failure Data Analysis for Condition Monitoring Application, Department of Mechanical Engineering, Indian Institute of Technology, New Delhi. Kegs. R. L., On-line Machine and Process Diagnostics, Annals of the CIRP. , 32(2), 469-473, 1984.

[2]V. Roy - S. Kumar from Inst. Eng. India Ser. C(April-June 2013) 94(2):187-195 DOI: 10.1007/s40032-013-0064-2

[3]Karl-Heinz Schumacher (2013), Multispindle Lathe. US patent \# 2013008702/2013

[4] In 2013, M. Moses \& Dr. Denis Ashok M. Tech, Mechatronic from School of Mechanical and Building Science, VIT University, Vellore, India 978-1-4673-6150-7/13/\$31.00 @2013 IEEE

[5]Special issue on Recent Advances in Flexible Automation, International Journal of Innovative Computing, Information and Control Volume 4, Number 3, March 2008 - ICIC International ${ }^{\circ} \mathrm{C} 2008$ ISSN 13494198Department of Mechanical Engineering, University of Auckland, Private Bag 92019, Auckland, New Zealand.

[6] Kriangkrai Waiyagan \& E.L.J. Bohez from Department of Design and Manufacturing Engineering, Asian Institute of Technology, P.O. Box 4, Klong Luang, 12120 Pathumthani, Thailand Ninth International Conference on Computer Aided Design and Computer Graphics (CAD/CG 2005) 0-7695-2473-7/05 \$20.00 @ 2005 IEEE

[7]PrakashN.Parmar1,Prof.N.C.Mehta2,Prof.ManishV.Trivedi3,’Investigat i on Automation of Lathe Machine”, International Journal of Emerging Technology and Advanced Engineering (IJETAE), Volume 4, Issue 5 , May 2014

[8] We have also used following links, http://en.wikipedia.org/wiki/Numerical_control http://en.wikipedia.org/wiki/Lathe http://www.epa.gov/ozone/title6/609/technicians/retrguid.html 